\title{
Automatic Mexico Gulf Oil Spill Detection from Radarsat-2 SAR Satellite Data Using Genetic Algorithm
}

\author{
Maged MARGHANY \\ Geospatial Information Science Research Centre, Faculty of Engineering, \\ University Putra Malaysia, Serdang, Selangor, Malaysia \\ e-mail: magedupm@hotmail.com
}

\begin{abstract}
In this work, a genetic algorithm is exploited for automatic detection of oil spills of small and large size. The route is achieved using arrays of RADARSAT-2 SAR ScanSAR Narrow single beam data obtained in the Gulf of Mexico. The study shows that genetic algorithm has automatically segmented the dark spot patches related to small and large oil spill pixels. This conclusion is confirmed by the receiveroperating characteristic (ROC) curve and ground data which have been documented. The ROC curve indicates that the existence of oil slick footprints can be identified with the area under the curve between the ROC curve and the no-discrimination line of $90 \%$, which is greater than that of other surrounding environmental features. The small oil spill sizes represented $30 \%$ of the discriminated oil spill pixels in ROC curve. In conclusion, the genetic algorithm can be used as a tool for the automatic detection of oil spills of either small or large size and the ScanSAR Narrow single beam mode serves as an excellent sensor for oil spill patterns detection and surveying in the Gulf of Mexico.
\end{abstract}

Key words: oil spills, small and large sizes of oil spill, Gulf of Mexico, RADARSAT-2 SAR, ScanSAR Narrow Beam, genetic algorithm.

Ownership: Institute of Geophysics, Polish Academy of Sciences;

(C) 2016 Marghany. This is an open access article distributed under the Creative Commons Attribution-NonCommercial-NoDerivs license,

http://creativecommons.org/licenses/by-nc-nd/3.0/. 


\section{INTRODUCTION}

In recent years, there has been an explosive increase in the scope of incidents of marine pollution. The Deepwater Horizon oil spill in 2010, for instance, is the worst marine pollution disaster that has occurred in the history of the petroleum industry (Fig. 1).

This disaster produced three months of oil flows in the coastal waters of the Gulf of Mexico. The Deepwater-Horizon oil spill has serious effects on feeble maritime spices, wildlife habitats, fishing in the Gulf', the coastal ecology (Fig. 2), as well as the tourism industry. For instance, the immediate impacts were severe, with oil-soaked birds (Fig. 2a), fish, and turtles (Fig. 2b) washing up on shore along the coast. Generally, oil spill pollution can cause tremendous destruction in marine ecosystems. As a result, oil spill that floats on top of the water, in addition to decreasing fauna populations, affects the food chain in the ecosystem (Alpers 2002, Brekke and Solberg 2005, Garcia-Pineda et al. 2013, Xu et al. 2014). In fact, an oil spill reduces the amount of sunlight that penetrates the water, thereby limiting the photosynthesis of marine plants and phytoplankton. Moreover, when marine mammals, for instance, are exposed to an oil spill, their insulating capacities are reduced, thus making them more vulnerable to temperature variations and much less buoyant in seawater. The oil coats the fur of sea otters and seals, reducing its insulation capacity and leading to body temperature variations and hypothermia. Ingestion of the oil causes dehydration and damage

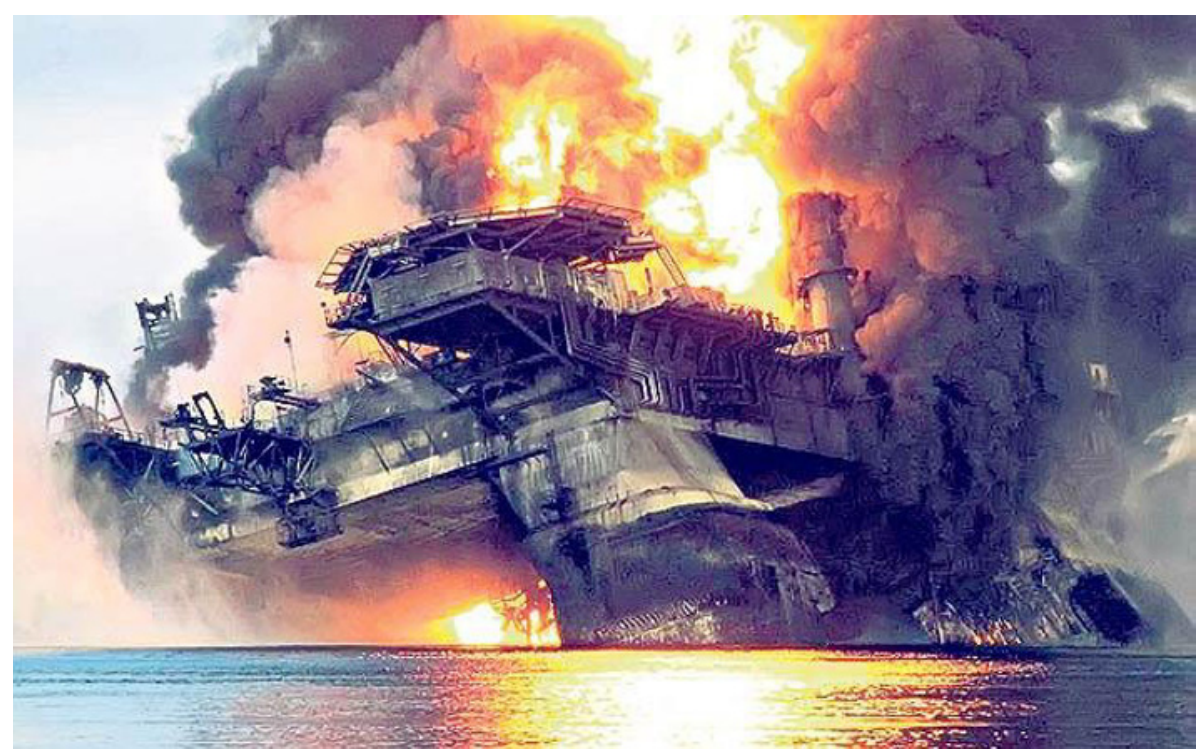

Fig. 1. Oil spill disaster in Gulf of Mexico. 
(a)

(b)

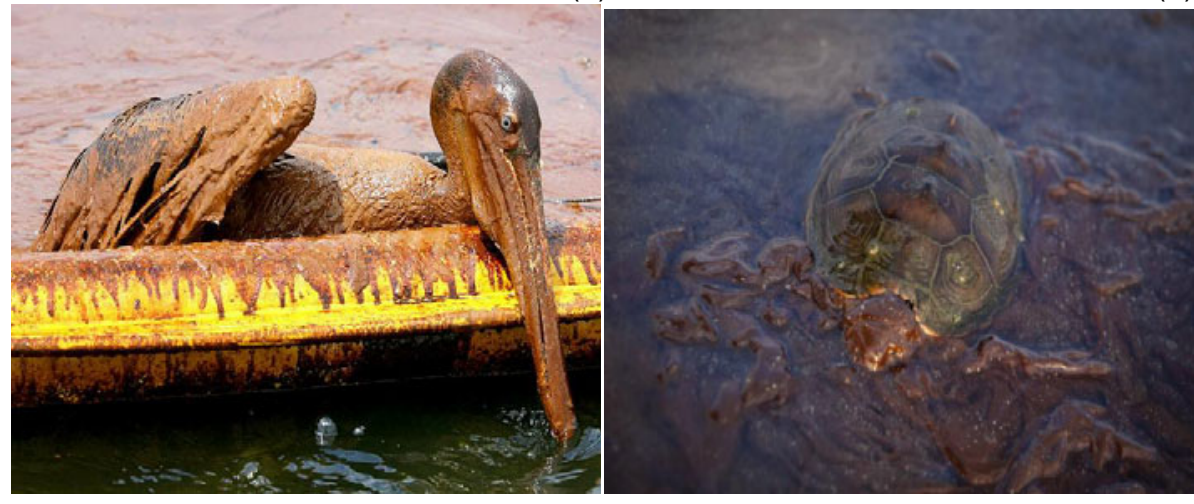

Fig. 2. Gulf oil disaster impacts on coastal ecology: (a) birds, and (b) turtle.

to the digestive system (Fiscella et al. 2000). Moreover, the oil spill and its cleanup have caused a variety of health problems. Deepwater Horizon spilled nearly five million barrels of oil, constituting the world's most massive accidental marine oil spill. Oil spills are difficult to bring under control because of the influence of coastal hydrodynamics, such as waves, currents, and tides. Therefore, advanced technologies are needed to achieve the accurate surveying, and control of marine oil pollution (Marghany 2013).

Numerous dissimilar sorts of sensor are conventionally used to detect and monitor oil spills in the ocean and were used during the Deepwater Horizon spill. These sensors are either mounted on satellite platforms or airborne. Like synthetic aperture radar (SAR), the microwave radiometer, the ultraviolet radiometer, as well as visible and near infrared radiometers are mounted on the satellite platform. Therefore, airborne remote sensing platforms, which include multispectral expert systems, hyperspectral airborne sensors, and airborne thermal infrared spectrometers, are also important. Each sensor exploits different physical properties of oil spill and its surrounding sea environment conditions (Cococcioni et al. 2012, Zhang et al. 2014).

Moderate Resolution Imaging Spectroradiometer (MODIS) aboard Terra (2000-present) and Aqua (2002-present) satellites provides global coverage twice daily in near-real time and is equipped with two $250-\mathrm{m}$ and five $500-\mathrm{m}$ resolution bands. MODIS 250-m resolution data used to detect oil spills in the Gulf of Mexico, which displayed dark contrast against the bright background. In the presence of sun glint, which is strongly dependent upon the solar geometry and the wave fields, oil impacted areas are well visualized with high contrast compared to oil-free areas. In the absence of sun glint, the contrast between oil slick and background depends on their different spectral 
characteristics. Therefore, optically remotely sensed data like MODIS' and AVIRIS' could be used to estimate oil slick thickness. Oil slick with different thickness showed different visual characteristics and led to different spectral reflectance within the visible light wavelength (Zhao et al. 2014). In this regard, oil slick thickness and oil-to-water emulsion ratios are key spill response parameters for containment/cleanup. Further, the near infrared spectral library of AVIRIS (Airborne Visible/Infrared Imaging Spectrometer) data can be used to quantitatively derive the thick $(>0.1 \mathrm{~mm})$ slicks. Consequently, a multispectral expert system based on MODIS and AVIRIS used a neural network and provided rapid response of oil spill thickness class maps using a neural network technique (Zhao et al. 2014).

Nevertheless, MODIS data cannot detect small areas of oil spill due to the limited resolution. Additional, heavy cloud covers do not allow for precise detection of oil spills in MODIS data. Likewise, oil spill detection algorithms based on thermal signature will not efficiently succeed in isolating oil spill pixels, which can be easily mistaken for cloud edges. Under these circumstances, Grimaldi et al. (2011) have developed a new algorithm, based on the general robust satellite technique (RST) approach, for automatic nearreal-time oil spill detection and continuous monitoring (i.e., in both daytime and nighttime) by using MODIS satellite data. They found that the RST algorithm was enabled to overcome possible false-positive problems related to not well-recognized cloud edges and sea surface local cooling effects that often reduce the reliability of the retrieval.

As noted by Marghany and Hashim (2011), synthetic aperture radar (SAR) allows for the improvement of oil spill detection using various approaches. The SAR tools for the detection and surveying of oil spills include boats, airplanes, and satellites (Zhang et al. 2012). Vessels can detect oil spills at sea, covering relatively limited areas of approximately $2500 \mathrm{~m} \times$ $2500 \mathrm{~m}$, when they are equipped with navigation radar (Zhang et al. 2011). Because they can probe broader areas, airplanes and satellites are the primary tools that are used to investigate sea-based oil pollution (Skrunes et al. 2012). Several SAR sensors have been deployed for oil spill detection and surveying. Such data have been collected by ERS-1/2 (Brekke and Solberg 2005), ENVISAT (Marghany 2013), ALOS (Zhang et al. 2012), RADARSAT-1/2 (Zhang et al. 2012, Xu et al. 2014), and TerraSAR-X (Velotto et al. 2011), and these data have been used on a global scale to identify and monitor the Deepwater Horizon oil spill. Furthermore, airborne SAR sensors such as the Uninhabited Aerial Vehicle Synthetic Aperture Radar (UAVSAR, operated by JPL, L-band) which has a 22-km-wide ground swath at incidence angles of $22^{\circ}$ to $65^{\circ}$ (Zhang et al. 2012) and E-SAR (operated by DLR, multi-band) have also proven their excellent potential for monitoring coastal zone oil pollution. Recently, multipolarimetric high reso- 
lution SAR data have become a field of intensive research for oil spill detection (Skrunes et al. 2012, Shirvany et al. 2012).

SAR sensors are imaging oil spill based on Bragg scattering theory. Bragg scattering is a significant concept to understand the radar signal interaction with ocean surface. Parenthetically, the presence of capillary wave will produce backscatter that assists radar in imaging sea surface. Short gravity and capillary waves by the oil spill are damped by dynamic elasticity of the water surface, that is, by changes in surface tension which occur when the surface is stretched or compressed (Alpers 2002, Marghany et al. 2009, Zhang et al. 2014). As stated by Caruso et al. (2013), the imaging of oil on the sea surface with SAR data are function of the damping influence of the oil on the Bragg waves. Unfortunately, the reduced radar backscatter on the sea surface is not unique to oil. Gade et al. (1998) stated that low winds, biogenic films, wind sheltering by land or oceanic structures, grease ice, internal waves, ship wakes, and convergence zones also generate zones of reduced SAR backscatter (Fiscella et al. 2000). Moreover, thunderstorms, rain, and atmospheric and oceanic fronts can mask surface roughness or produce the so-called "lookalike" features (Caruso et al. 2013).

Ocean surface wind pattern plays tremendous role for oil spills imaging in SAR data. When ocean surface winds are calm, surface gravity waves disappear, the return radar backscatter is low, and the ocean surface appears featureless and uniformly dark across the image (Alpers 2002, Brekke and Solberg 2005, Zhang et al. 2014). As the winds increase to about $3 \mathrm{~m} \mathrm{~s}^{-1}$, biogenic slicks begin to appear. Biogenic surface slicks, such as those produced by plants and animals in the ocean, can also dampen radar return and cause look-alike false alarms for oil detection. At the lower end of this range, biogenic slicks blend in with the low wind zones of the SAR image (Gade et al. 1998). When the winds reach $2-3 \mathrm{~m} \mathrm{~s}^{-1}$, these slicks begin to highlight oceanic convergence zones along fronts and eddies. At these speeds, it is often difficult to distinguish biogenic slicks from anthropogenic oil or natural seeps (Fiscella et al. 2000). Once the winds begin to exceed $3 \mathrm{~m} \mathrm{~s}^{-1}$, the biogenic slicks start to disappear and the contrast between oil and the sea surface is very strong (Alpers 2002). When the winds continue to increase, the short surface waves produce stronger radar backscatter. At the same time, as the wind speed is greater than about $8-10 \mathrm{~m} \mathrm{~s}^{-1}$, mixing by strong wind and/or wave action inhibits the formation of a surfactant layer, resulting in uniformly strong backscatter in all areas of an image, so that oil cannot be detected (Brekke and Solberg 2005, Caruso et al. 2013).

The detectability of oil with SAR is also a function of the sensor configuration. For C-band SAR, the detectability relies on polarization, incidence angle, spatial resolution, and noise equivalent sigma zero (Cheng et al. 2011). For single polarization images, VV-polarization produces better re- 
sults than HH-polarization. The backscatter intensity decreases with increasing incidence angle; therefore, small spills cannot be discriminated with lower-resolution beam modes. Although the NESZ (a measure of sensitivity of the SAR system) potentially limits the effectiveness at high incidence angles, the effects of wind speed are more important (Cheng et al. 2011).

Consequently, the highly accurate detectability of oil with SAR is exposed to the identification of oil spill parameters. However, the detailed parameters of oil spill are a challenging task to be identified because of complicated sea surface statutes and smoothing interaction of oil spill with SAR signal. Mainly, the oil spill can be classified as: light sheen, silver sheen, rainbow sheen, brown oil, mousse, black oil, streamers, tar balls, tar mats, and pancakes. Zhang et al. (2014) declared that dielectric constant (permittivity) is a significant key of oil spill parameter recognition. It describes the material's capability of holding electro-magnetic energy or polarizing, which is helpful in identifying the types and conditions of the oil. During Deepwater Horizon oil-spill accident, the extreme amount of oil leakage (approximately $700000 \mathrm{~m}^{3}$ ) and the thickness of oil film/emulsion are sufficient to significantly affect the permittivity of sea surface at the frequency of L-band (approximately $24 \mathrm{~cm}$ ).

Other oil spill parameters include area, average of normalized radar cross-section (NRCS) inside the dark area and in limited area outside the dark area (Topouzelis et al. 2009a). Then the statistical descriptions of oil spill dark patches are estimated based on standard deviation, as mean, minimum and maximum, in relation to the SAR scene (Brekke and Solberg 2005). The statistical descriptions are used to estimate, for example, the intensity ratio of dark patch mean value to scene's mean value and the intensity ratio of dark patch standard deviation value to scene's standard deviation value (Topouzelis et al. 2009b) and Guo and Zhang (2014). Supplementary, the physical oil spill parameters can be commonly categorized based on: (i) the geometric features of oil spill (e.g., area, perimeter, complexity), (ii) the statistical of physical manners of oil spills (e.g., mean or max backscatter value, standard deviation of the dark formation or a bigger surround area), and (iii) the oil spill circumstance in the SAR image (e.g., number of other dark formations in the image, or presence of ships) (Topouzelis et al. 2009b, Fingas and Brown 2014).

Nevertheless, oil spill monitoring and detection using SAR technology and data are not trivial tasks because of the difficulties in discriminating between oil spills and other look-alike features such as low wind zones and shadows which appear as dark patches in SAR data. Despite the difficulties of automatically detecting oil spills using SAR data, significant achievements have been accomplished in recent decades. Frate et al. (2000) have proposed the semi-automatic detection of oil-spills using a neural network, 
of which the primary parameter is a vector that describes the features of an oil-spill candidate. Topouzelis et al. (2007, 2009b) and Marghany and Hashim (2011) have proven that a neural network can be used to precisely discriminate between oil spills and look-alikes in SAR data. Topouzelis et al. (2007) have used neural networks for both dark formation detection and oilspill classification. In their experiment, $94 \%$ detection of the dark formation segmentation and $89 \%$ accuracy of classification were obtained. Topouzelis et al. (2009a) have also performed a detailed examination of the robustness of the results archived based on combinations derived from 25 features that are commonly used for the identification of oil spills. They found that a combination of 10 features yields the most accurate results.

Topouzelis et al. (2009b) have reported that most studies use low resolution SAR data, such as quick-look datasets, which have a nominal spatial resolution of $100 \mathrm{~m} \times 100 \mathrm{~m}$, to detect oil spills. For this purpose, quick look data are sufficient for monitoring large scale areas of $300 \mathrm{~km} \times 300 \mathrm{~km}$. However, they cannot effectively detect small, fresh spills.

Marghany and Hashim (2011) have developed comparable automatic detection procedures for oil spill pixels in Multimode RADARSAT-1 SAR data (Standard Beam S2, Wide Beam W1, Fine Beam F1). These procedures include supervised post classification (Mahalanobis) and a neural network $(\mathrm{NN})$. They found that the NN exhibited superior performance for the automatic detection of oil spills in RADARSAT-1 SAR data, compared to the Mahalanobis classification, with a standard deviation of 0.12 . Recently, however, Skrunes et al. (2012), have reported that there are several disadvantages associated with oil spill detection using current SAR sensors. They stated that SAR sensors cannot detect the thickness distribution, volume, oilwater emulsion ratio or chemical properties of an oil slick. Instead they recommended the use of multi-polarisation observations, such as the data acquired by the RADARSAT- 2 and TerraSAR-X satellites. They demonstrated that multi-polarisation data can accurately discriminate between mineral oil slicks and biogenic slicks. Garcia-Pineda et al. (2013) have developed the Textural Classifier Neural Network Algorithm (TCNNA) to map oil-spills by combining ENVISAT ASAR data and wind model outputs (CMOD5) using a combination of two neural networks. They have reported that TCNNA can be used as a semi-automatic tool for oil spill detection and provides a rapid and precise overview of oil spill footprints in ENVISAT ASAR data. They have also reported that TCNNA performance is dependent on wind conditions.

Currently, Marghany (2015) developed optimization tool of Entropy based Multi-Objective Evolutionary Algorithm (E-MMGA) which is based on Pareto optimal solutions for oil spill automatic detection from CosmoSkymed satellite data. He concluded that an optimization entropy based Mul- 
ti-Objective Evolutionary Algorithm provides an accurate pattern of oil slick in Cosmo-Skymed satellite data.

However, small-size oil spills are not detected because most of SAR satellites or airbone SARs overpassed the polluted zone after the spills have grown under the influence of the ocean surface dynamic changes. In addition, fresh oil spills of few-meter (e.g., $3 \mathrm{~m}$ ) length cannot be detected with SAR pixel resolution of 6 to $12.5 \mathrm{~m}$. The main question can be raised up whether such a GA is able to detect a small oil spill spreading between the large ones.

We hypothesised that dark (small or large) spot pixels, in SAR data, regardless of whether they represent oil spills, look-alikes, or low wind zones, can be automatically detected and discriminated using the genetic algorithm (GA). However, previous studies have applied post classification techniques (Marghany and Hashim 2011) or artificial neural networks (Topouzelis et al. 2009b, Garcia-Pineda et al. 2013) which are considered to be semiautomatic techniques only for a large area of oil spill. The primary objective of this work is to investigate the use of the GA (Marghany 2013) for the automatic detection of large or small oil spills in RADARSAT-2 SAR satellite data.

\section{METHODS}

\subsection{Case study}

The Deepwater Horizon, an offshore oil-drilling rig, exploded on the night of 20 April 2010, while working on a wall on the seafloor in the Gulf of Mexico. The blast occurred 41 miles from the Louisiana coast and above the water depth of $1500 \mathrm{~m}$ (Fig. 3a). For nearly three months, oil leaked from per

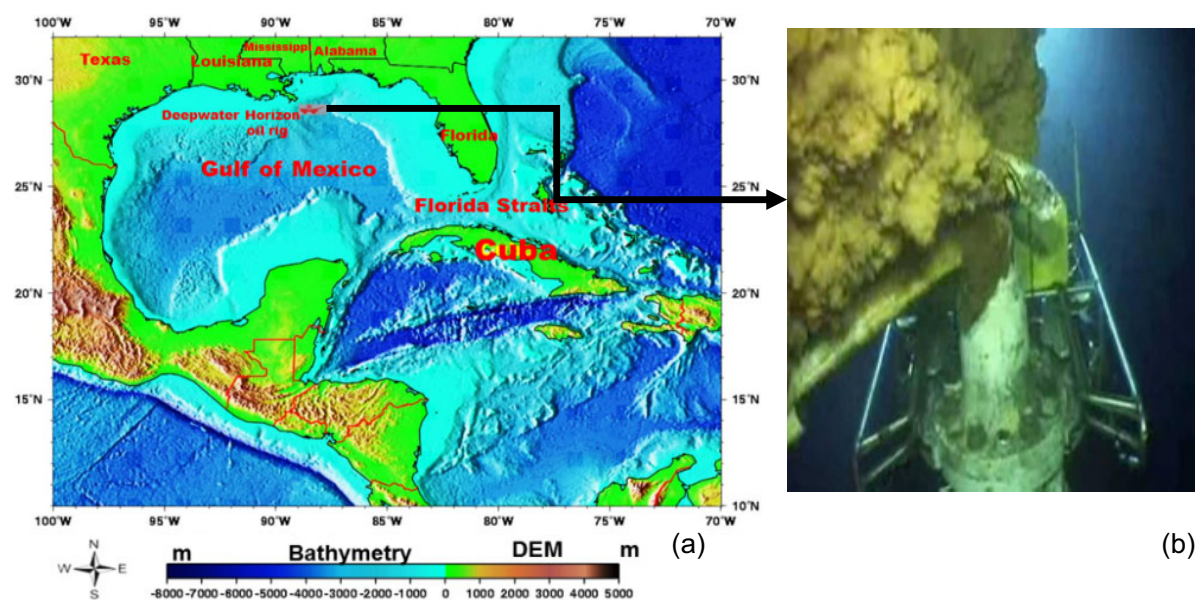

Fig. 3. Illustrations of: (a) bathymetry, and (b) location of Deepwater Horizon Blowout, Gulf of Mexico. 
day (42 gallons per barrel) (Fig. 3b). The oil continued to flow until mid-July 2010. In all, the well spilled 4.9 million gallons, creating the largest offshore oil spill in history. Furthermore, the oil slick spread quickly over the surface of the ocean, covering $1500 \mathrm{~km}^{2}$ (580 sq miles) by 25 April and over $6500 \mathrm{~km}^{2}$ (2500 sq miles) by the beginning of May. An oil platform located $70 \mathrm{~km}$ from the coast of Louisiana sank on Thursday, 22 April 2010, in the Gulf of Mexico, spilling oil into the sea (RADARSAT-2 2014).

\subsection{Data set}

In this study, RADARSAT-2 SAR data acquired by RADARSAT-2 operating in ScanSAR Narrow single beam mode (Table 1) on 27 April 2010, 1 May 2010, and 3 May 2010 are investigated for oil spill detection in the Gulf of Mexico. The satellite is equipped with synthetic aperture radar (SAR) with multiple polarisation modes, including a fully polarimetric mode in which $\mathrm{HH}, \mathrm{HV}, \mathrm{VV}$, and $\mathrm{VH}$ polarised data are acquired. Its highest resolution is $1 \mathrm{~m}$ in Spotlight mode ( $3 \mathrm{~m}$ in Ultra Fine mode) with a $100 \mathrm{~m}$ positional accuracy requirement. In the ScanSAR Narrow beam mode, the SAR has a nominal swath width of $500 \mathrm{~km}$ and an imaging resolution of $100 \mathrm{~m}$ (MDA 2009). Finally, the wind speed data are retrieved from the studies of Shay et al. (2011), Walker et al. (2011), Garcia-Pineda et al. (2013), and NOAA OR\&R (2013). The validation of oil spill occurrences in RADARSAT-2 SAR data was made using the ground information collected by NOAA/NESDIS (2013). The repeat cycle of ScanSAR Narrow beam mode is 12 days with 4 looks. Its incidence angle ranges between $20^{\circ}$ and $46^{\circ}$ (Table 1).

Table 1

RADARSAT- 2 characteristics

\begin{tabular}{|l|c|}
\hline RADARSAT-2 characteristics & Values \\
\hline Bandwidth [MHZ] & 100 \\
Polarization & $\mathrm{HH}$ \\
Nominal resolution [m] & $50 \times 50$ \\
Center frequency [GHz] & 5405 \\
Swath width [km] & $300-500$ \\
Repeat cycle [days] & 12 \\
Looks & 4 \\
Incident angle $\left[{ }^{\circ}\right]$ & $20-46$ \\
\hline
\end{tabular}




\subsection{Genetic algorithm}

The genetic algorithm (GA) is a powerful tool in the field of artificial intelligence in computer science. The GA is considered to be an optimal search and evolutionary algorithm that mimics the processes of natural selection. In other words, the GA spawns solutions to optimising problems using techniques inspired by natural evolution, such as inheritance, mutation, selection, and crossover (Sivanandam and Deepa 2008).

As described by Kahlouche et al. (2002), the genetic algorithm (GA) differs from a classification algorithm. In a classification algorithm, a single point is generated in each iteration. Moreover, a classification algorithm chooses the next point in the classification using a deterministic computation. In contrast, the genetic algorithm (GA) generates a population of cells in each iteration, of which one particular cell in the population most closely approaches the optimal solution (Fig. 4). Moreover, GA implements probabilistic transition rules not deterministic rules as in classification algorithms (Marghany 2013).

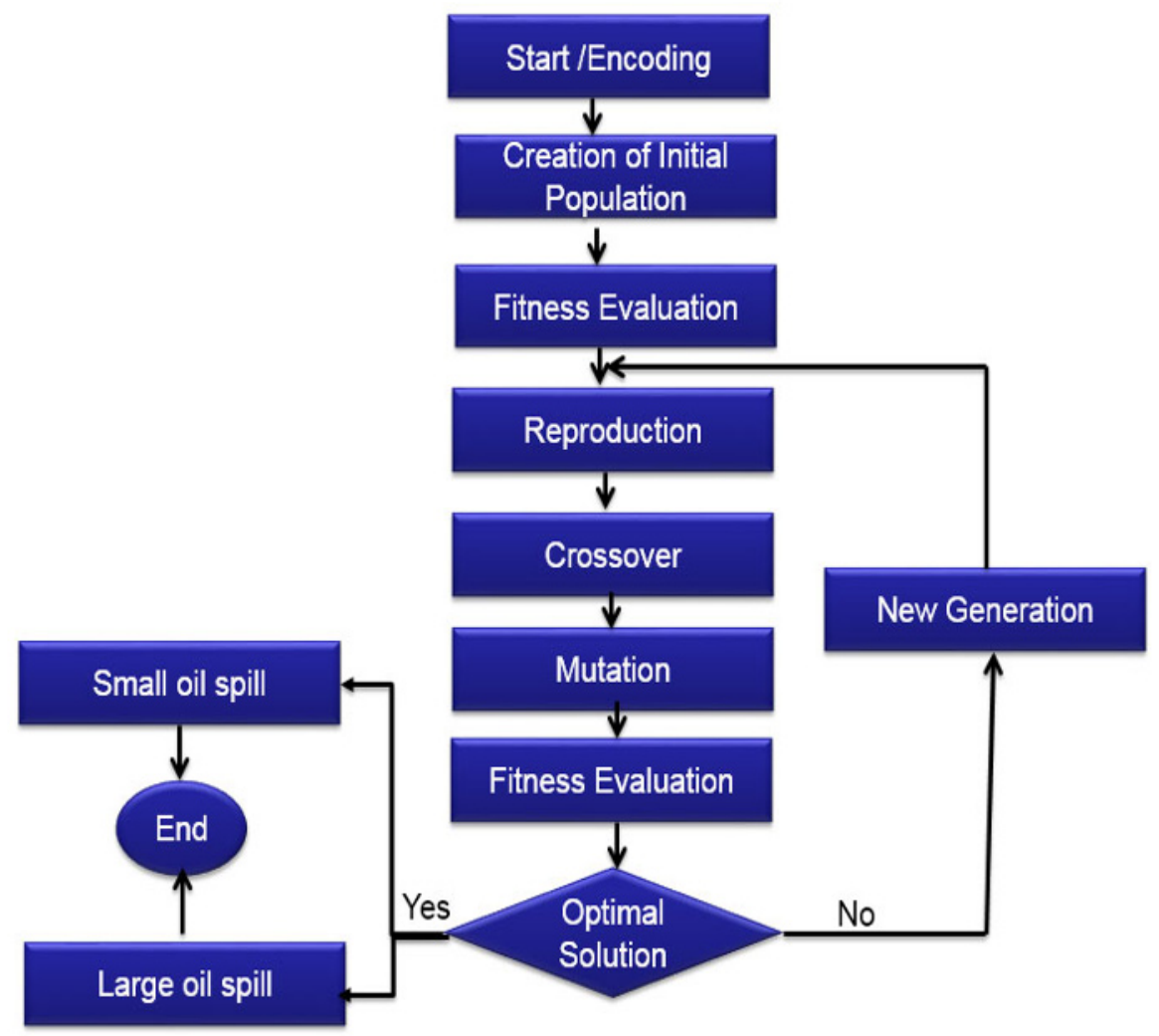

Fig. 4. Flow chart of genetic algorithm search pattern for small and large oil spills. 
A large population of random chromosomes of different SAR backscatters is created at the beginning of one iteration of a genetic algorithm. Each one, when decoded, will represent a different solution to the problem at hand. There are $N$ chromosomes in the initial population. Then, the following steps are repeated until sufficiently accurate solution is obtained: (i) Test each chromosome of the SAR backscatters to determine how effective it is as a solution to the problem at hand, and assign a fitness score accordingly; (ii) Select two members of the current population. The probability of being selected is proportional to the chromosomes' fitness; (iii) In accordance with the crossover rate, crossover the bits from each chosen chromosome at a randomly chosen point; (iv) Loop over the bits of the chosen chromosomes and modify them in accordance with the mutation rate; (v) Repeat steps (ii), (iii), and (iv) until a new population of $N$ members has been created.

\subsubsection{Data organisation}

Let the entire backscatter set of dark patches in the SAR data be $\left[\beta_{1}, \beta_{2}, \beta_{3}, \ldots, \beta_{K}\right]$, where $K$ is the total number of backscatters representing dark patches in the SAR data. Therefore, $K$ is composed of genes that represent the backscatters $\beta$ of the dark patches and their surrounding environment, and the genetic algorithm is begun with the population initialisation step. Following Marghany (2013), a constrained multi-objective problem for oil spill discrimination in SAR data encompasses more than one objective and constraint, namely, look-alikes; such features include currents, eddies, upwelling or downwelling zones, fronts and rain cells. The general form of the problem is adapted from Sivanandam and Deepa (2008) and can be described as follows.

Minimise

$$
f(\beta)=\left[f_{1}(\beta), f_{2}(\beta), \ldots, f_{k}(\beta)\right]^{T}
$$

subject to the following constraints:

$$
\begin{gathered}
g_{i}(\beta) \leq 0, \quad i=1,2,3, . . I, \\
h_{j}(\beta) \leq 0, \quad j=1,2,3, \ldots J, \\
\beta_{L} \leq \beta \leq \beta_{U},
\end{gathered}
$$

where $f_{i}(\beta)$ is the $i$-th pixel of backscatters $\beta$ in the SAR data, and $g_{i}(\beta)$ and $h_{j}(\beta)$ represent the $i$-th and $j$-th constraints on the backscatter in the row direction and the column direction, respectively. $\beta_{L}$ and $\beta_{U}$ are the lower and upper limits on the backscatter values. The transition rules for the automatic oil spill detection capability of the cells are designed based on the input of various backscatter values $\beta$ to define the conditions required for a given 
pixel to be identified as an oil-spill pixel among the neighbouring pixels of a kernel with a window size of $7 \times 7$ pixels and lines which preserve the boundary and edges of oil spill pixels (Marghany 2001). These rules can be summarised as follows:

$\square$ IF the test pixel represents the sea surface, OR current boundary features THEN $\beta \geq 0$, and the test pixel is not an oil spill pixel.

口 IF the test pixel represents a dark patch (low-wind zone, OR biogenic slick OR shear zone ) and $\beta \leq 0$, THEN the pixel is identified as an oil spill pixel.

口 IF the identified oil spill pixels are small (i.e., smaller backscatter is less than the main set of oil spill pixels) and $\beta_{\text {small }}<\beta$, THEN the pixel is identified as a small oil spill size.

\subsubsection{Population initialisation}

Let $P_{i}^{j}$ be a gene that corresponds to the backscatter of a dark pixel and or its surrounding pixels. Consequently, the distribution of randomly selected $P_{i}^{j}$ represents the backscatter variations of both the dark patches and their surrounding environmental pixels. Here, $i$ varies from 1 to $K$ and $j$ varies from 1 to $N$, where $N$ is the population size.

\subsubsection{The fitness function}

Following Kahlouche et al. (2002) and Marghany (2013), a fitness function is selected to determine the similarity of each individual backscatter corresponding to dark patches in RADARSAT-2 SAR data. The backscatters of the dark patches in the RADARSAT-2 SAR data are denoted by $\beta_{i}$, where $i=1,2,3, \ldots, K$, and the initial population $P_{i}^{j}$, where $j=1,2,3, \ldots, N$ and $i=1,2,3, \ldots, K$. Formally, the fitness value $f\left(P^{j}\right)$ of each individual member of the population is computed as follows:

$$
f\left(P^{j}\right)=\left[\sum_{i=1}^{K}\left|P_{i}^{j}-\beta_{i}\right|\right]^{-1}, \quad j=1, \ldots, N,
$$

where $N$ is the total number of individuals in the population, and $K$ is the number of individuals from the population considered in the fitness determination. Generally, eq. 5 is used to determine the level of similarity amongst dark patches that correspond belong to oil spills in the RADARSAT-2 SAR.

\subsubsection{The selection step}

The key element of the selection step of the genetic algorithm is to select the fittest individuals $f\left(P^{j}\right)$ from the population $P_{i}^{j}$. The threshold value $\tau$ is determined by the maximum fitness value of the population, $\operatorname{Max} f\left(P^{j}\right)$, and the 
minimum fitness value of the population, $\operatorname{Min} f\left(P^{j}\right)$. In subsequent generations, this step defines of the populations $P$. The fittest individuals that are most likely to present dark patches in the RADARSAT-2 SAR data are those with values greater than the threshold $\tau$, which is defined as

$$
\tau=0.5\left[\operatorname{Max} f\left(P^{j}\right)+\operatorname{Min} f\left(P^{j}\right)\right] .
$$

Equation 6 is used for the selection step to determine the maximum and minimum acceptable values for the fitness of the population. This is considered to be the step in which the dark patch population is generated in the GA procedure.

\subsubsection{The reproduction step}

According to Sivanandam and Deepa (2008), the bulk of the calculation involved in the genetic algorithm lies in the reproduction step, which involves the implementation of the crossover and mutation processes on the backscatter population $P_{i}^{j}$ determined from the SAR data. The crossover operation constructs a population $P_{i}^{j}$ that will converge to solutions with high fitness. Thus, the closer the crossover probability is to 1 , the more rapid the convergence (Marghany 2013). In the crossover step, genes are interchanged between the chromosomes. A local fitness value is assigned to each gene as follows:

$$
f\left(P_{i}^{j}\right)=\left|\beta_{i}-P_{i}^{j}\right|
$$

The crossover between two individuals serves to preserve all individual populations of the first parent that have a local fitness greater than the average local fitness $f\left(P_{\mathrm{av}}^{j}\right)$ and replaces the remaining genes with the corresponding genes from the second parent. The average local fitness is defined by

$$
f\left(P_{\mathrm{av}}^{j}\right)=\frac{1}{K} \sum_{i=1}^{K} f\left(P_{i}^{j}\right) .
$$

Meanwhile, the mutation operator represents extraordinary random phenomena in the evolution process. It is possible that some useful genetic information may be lost from selected population during the reproduction step. To compensate for this potential loss, the mutation operator is applied to introduce new genetic information into the gene pool (Marghany 2013).

\subsubsection{Morphological operations}

Morphological operations are performed on selected individuals prior to the crossover and mutation processes. In the crossover process, the probability 
(a)

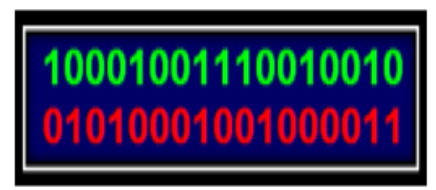

(b)

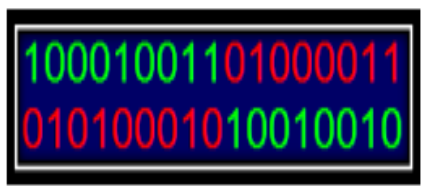

Fig. 5. Crossover process: (a) selected two random genes, and (b) output of crossover.

that any given pair of chromosomes will exchange their bits (Fig. 5a) is approximately 0.7 . Crossover is performed by selecting a random gene along the length of the chromosomes and swapping all genes after that point (Michalewicz 1994). In other words, a random bit is chosen, for example, the bit at position 9, and all bits after that point are swapped (Fig. 5b).

In the mutation process, the probability that the value of a given bit within a chromosome is flipped ( 0 becomes 1,1 becomes 0 ) is usually very low for binary encoded genes, perhaps 0.001 . Every time chromosomes are selected from amongst the population, the algorithm first checks whether the crossover has been applied, and the algorithm then iterates down the length of each chromosome, mutating bits if applicable (Davis 1991). This procedure is designed to exploit the connectivity property of the RADARSAT-2 SAR data. The morphological operations are implemented during the reproduction step as follows: (i) closing, followed by (ii) opening. The accuracy of the dark patch segmentations achieved in this manner depends on the size and shape of the structuring element. Therefore, a structuring kernel with square window size of $7 \times 7$ pixels is chosen to preserve the fine details of the oil spill present in the RADARSAT-2 SAR data (Sivanandam and Deepa 2008).

\section{RESULTS AND DISCUSSION}

An oil platform located $70 \mathrm{~km}$ from the coast of Louisiana sank on Thursday, 22 April 2010, in the Gulf of Mexico, spilling oil into the sea. In the RADARSAT-2 SAR Scan Narrow Beam (SCNB) data that were acquired at the time, the rapid growth of the oil slick footprint from 27 April 2010, to 5 May 2010, can be clearly seen (Fig. 6).

Figure 6 shows that oil slick and sheen extended across 19112 sq. miles $\left(49500 \mathrm{~km}^{2}\right)$ of the Gulf. In addition, it is worthy of note that the oil slick spun in a counter-clockwise direction. This behaviour is attributed to the influence of the Gulf Stream. Nevertheless, the RADARSAT-2 SAR data did not indicate that the oil-slick footprint coincided with the loop current in the Gulf of Mexico. According to Zangari (2010), the oil slick was one of the causes of the disconnection of the loop current in the Gulf of Mexico. 
(a)

(b)
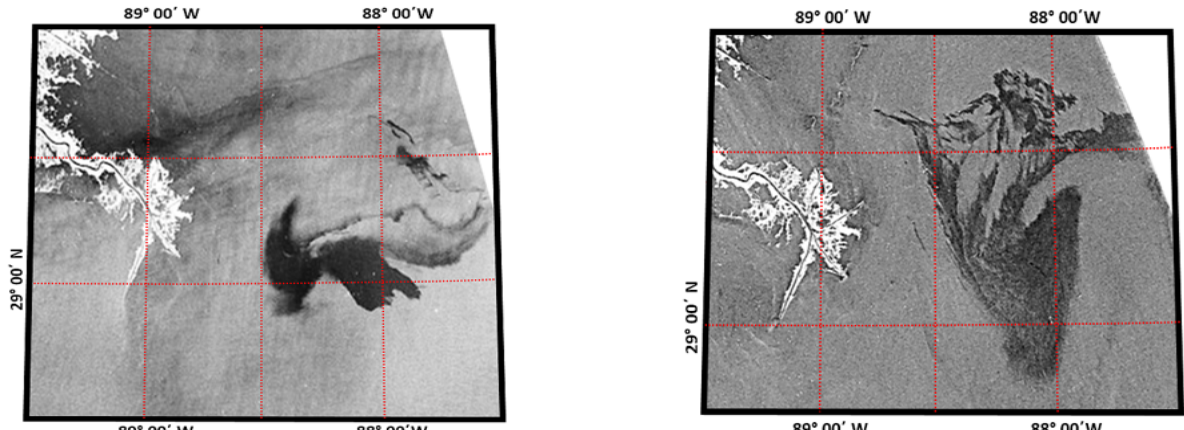

(c)

(d)
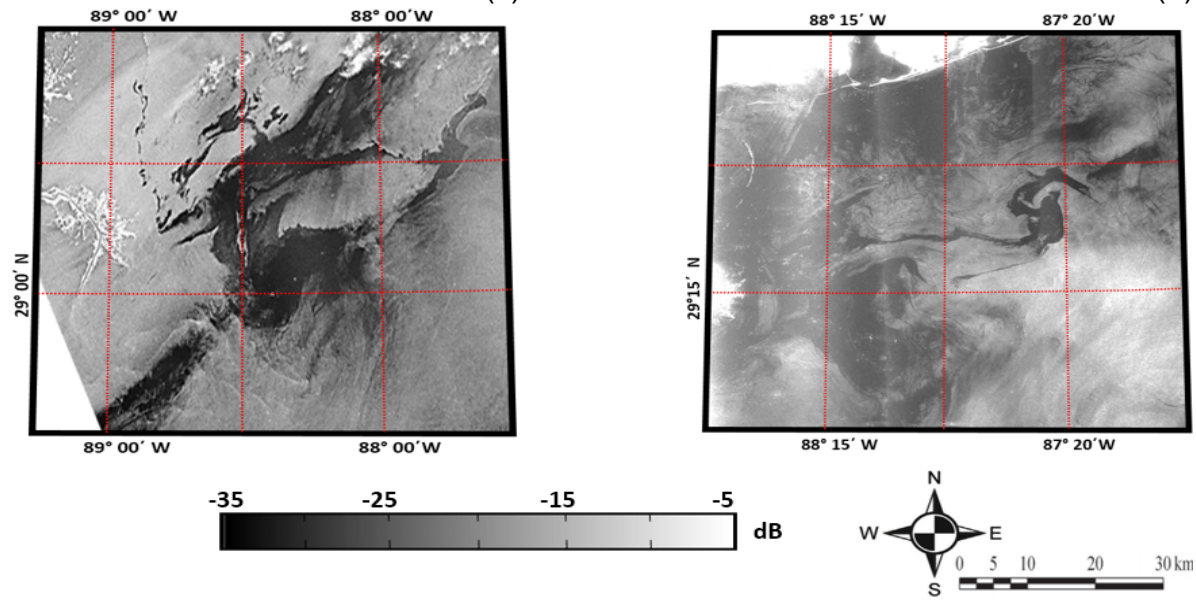

Fig. 6. RADARSAT-2 SAR Scan Narrow beam SCNB data on: (a) 27 April, (b) 1 May, (c) 3 May, and (d) 5 May 2010.

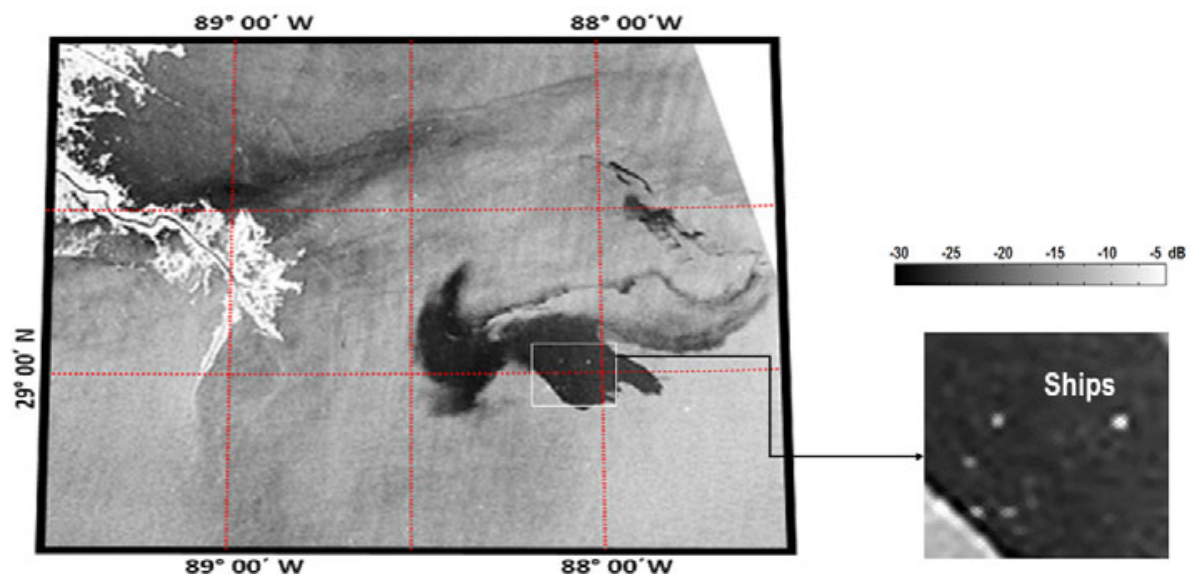

Fig. 7. Backscatter of ship pixels which are identified by white box. 
It is clear that the oil spill, which covered an area greater than $150 \mathrm{~km}^{2}$ in the Gulf of Mexico, had a darker tone than both the surrounding water and some boats in the area (Fig. 7). The data represent some regions that are located at the farther extent of the area that is probed by RADARDSAT-2 SAR Scan Narrow Beam (SCNB) with a revisit period. Figure 6 shows the variation in the average backscatter intensity along the oil slick footprint. The average backscatter intensity was damped by -30 to $-25 \mathrm{~dB}$ and decreased over time as the oil slick footprint was gradually increasing (Fig. 7). By contrast, ship footprints are characterised by a maximum backscatter of $-5 \mathrm{~dB}$ (Figs. 6 and 7) because the SCNB mode has nominal near and far resolutions of $7 \mathrm{~m}$ (MDA 2009).

Clearly, oil spill is portrayed in SCNB mode by shallower incidence angle ranges between $36^{\circ}$ to $46^{\circ}$ and the maximum wind speed of $10 \mathrm{~m} / \mathrm{s}$ (Fig. 8). Clearly, the backscatter increases with increasing wind speed, and decreases with increasing incidence angle. This study confirms the work of Cheng et al. (2011), Caruso et al. (2013), and Garcia-Pineda et al. (2013). However, Garcia-Pineda et al. (2013) stated that the ideal detection of oil spills in SAR images requires moderate wind speeds, not exceeding $6 \mathrm{~m} / \mathrm{s}$.

Neverthless, the SCNB mode beam date acquired on 3 and 5 May (Figs. 6c and d, respectively) can detect oil spill under extremely high wind speed of $10 \mathrm{~m} / \mathrm{s}$ (Fig. 8) which caused the intense turbulence of sea surface (Figs. 5c and d). This could be due to the extreme amount of oil leakage (ap-

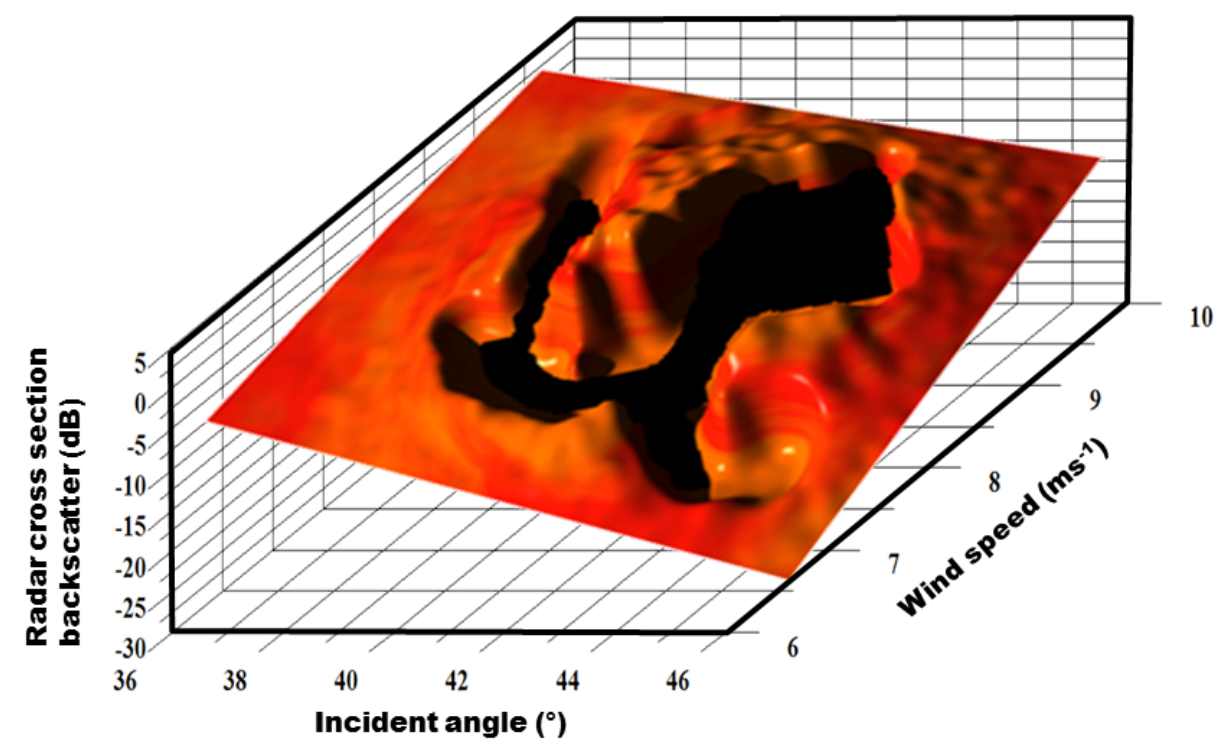

Fig. 8. Radar cross-section backscatter along oil slick locations, incident angle, and wind speed distribution during date of acquisitions. 
proximately 60000 barrels per day) which cannot be dissipated by such extreme wind and turbulent conditions. This study confirms the work of Garcia-Pineda et al. (2013).

The SCNB mode provides images of very wide swaths in a single pass of the satellite with single linear $\mathrm{HH}$ co-polarisation and a pixel spacing of 25 range $\times 25$ azimuth [m]. The SCNB mode provides coverage over the shallow incident angle range of $31^{\circ}$ to $47^{\circ}$. This data source was selected because of its large swath $(300 \mathrm{~km})$, acceptable pixel size, spacing $(25 \mathrm{~m})$, high temporal resolution ( $2 / 3$ side-lap pass within 7 days), and relatively low volume of data. The C-band and shallow incidence angle $\left(31^{\circ}-47^{\circ}\right)$ data have been found to be suitable for the identification of oil slick footprints. The sensitivity of the SAR backscatter measurements to the water surface roughness created by wind-induced ripples can be reduced by using $\mathrm{HH}$ polarisation and a large incidence angle (Ivanov et al. 2002, Choudhury and Chakraborty 2006). Furthermore, Ivanov et al. (2002) have confirmed that the RADARSAT-1 SAR, when operating in the ScanSAR Narrow mode with a swath width that exceeds $300 \mathrm{~km}$, is a promising tool for marine oil pollution detection.

Figure 9 provides an example of the crossover process with 10 individuals. Of these 10 individuals, the positive dark patches represent oil spill pixels, whereas the negative dark patches represent the surrounding pixels. Accordingly, every cell is compared to the other corresponding cells to determine whether its value is positive or negative (Figs. 9c and d). Further, the crossover process is begun with cell of small oil spill pixel which is dominated by a small backscatter (Fig. 9b). Further, the crossover process is begun with cell of small oil spill pixel which is dominated by a small backscatter (Fig. 9b).

According to Marghany (2013), in the GA procedure, a cell has a positive value and should be propagated to subsequent generations when the cell in the intermediate prototype has a value larger than zero and greater than the threshold value. Such cells represent an oil spill event in RADARSAT-2 SAR data. Subsequently, in crossover, the cells of small oil spill have been generated first because they are located along the edge of large oil spill cells. By contrast, a cell that has a negative value represents a look-alike feature. In such a case, the cell in the intermediate prototype has a value of less than zero and below the threshold value and this cell's influence on subsequent generations should be diminished. The variation in the cell value (positive or negative) is a function of the cell's dissimilarity with comparable cells (Davis 1991). This study confirms and extends the capabilities of the GA that were introduced by Kahlouche et al. (2002) and Marghany (2013).

Clearly, the genetic algorithm is able of discriminating dark oil spill pixels from the surrounding environment. In the algorithm's output, look-alike 
(a)

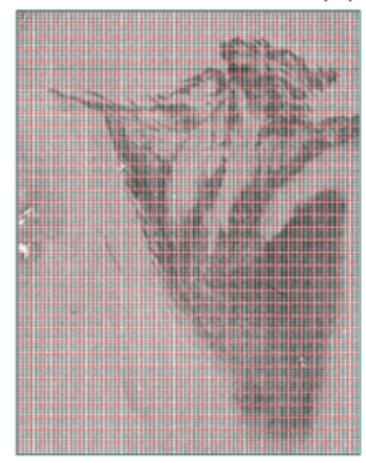

(b)

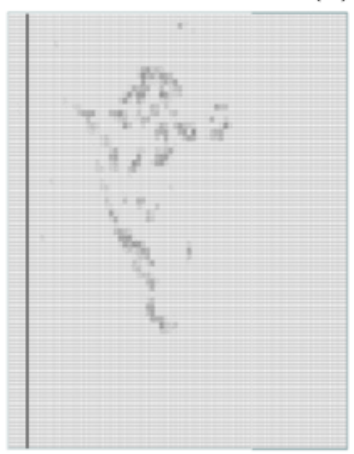

(d) (c)

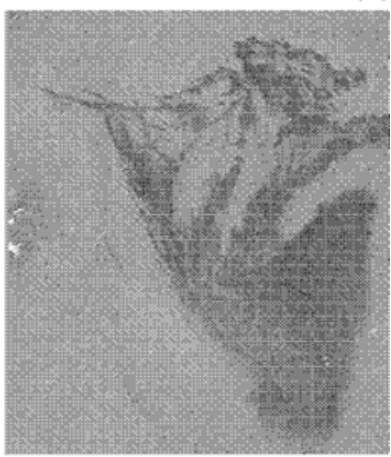

(e)
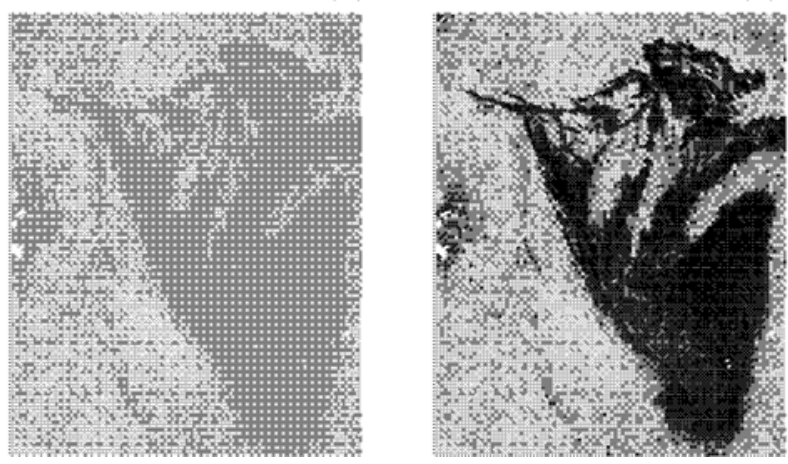

Fig. 9. Crossover procedures: (a) original data, (b) first individual small oil spill, (c) second individual large oil spill, (d) resulting from an individual prior cancellation, and (e) after cancellation.

features, low wind zones, rough patches on the sea surface and land, are indicated by white coloured regions, whereas oil spill pixels are marked in black (Fig. 10). Figure 10 presents the GA results in which $100 \%$ of the oil slick pixels in the test set were correctly classified. Figure 11 confirms the ability of the GA for automatic detection and discrimination of small oil spill sizes from the large oil spill. It is interesting to notice that small oil spill sizes are located out of the area of large ones or at the edge of large oil spill areas (Fig. 11). This is excellent evidence that the crossover process is commenced by searching and matching small cells of oil spills (Fig. 9b). After several iterations, the crossover process has reconstructed the full prototype of large oil spill cells (Figs. 9e, 10, and 11).

This study differs from the previous work performed by Marghany and Hashim (2011) because this work presents an automatic detection based on GA, whereas the study performed by Marghany and Hashim (2011) used an 
(a)

(b)
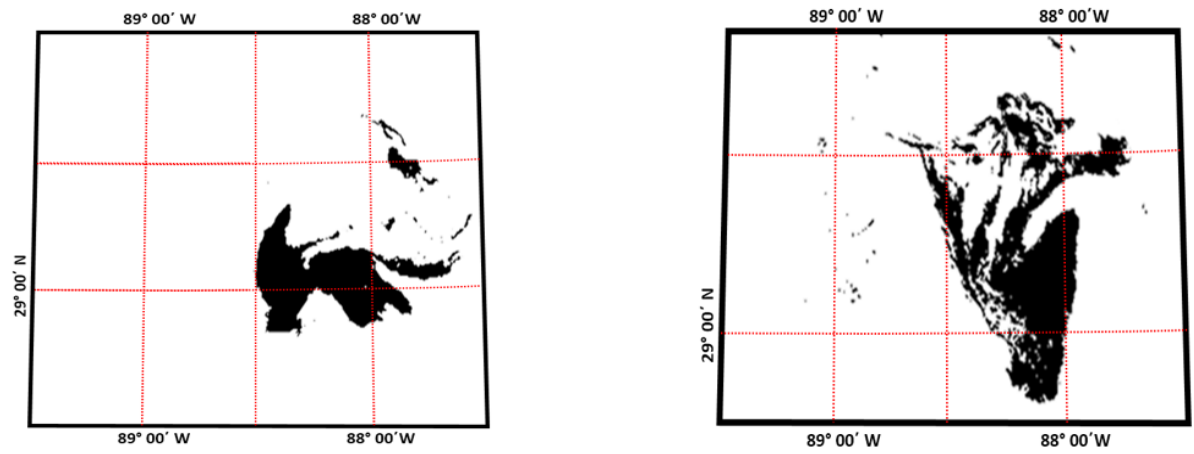

(c)

(d)
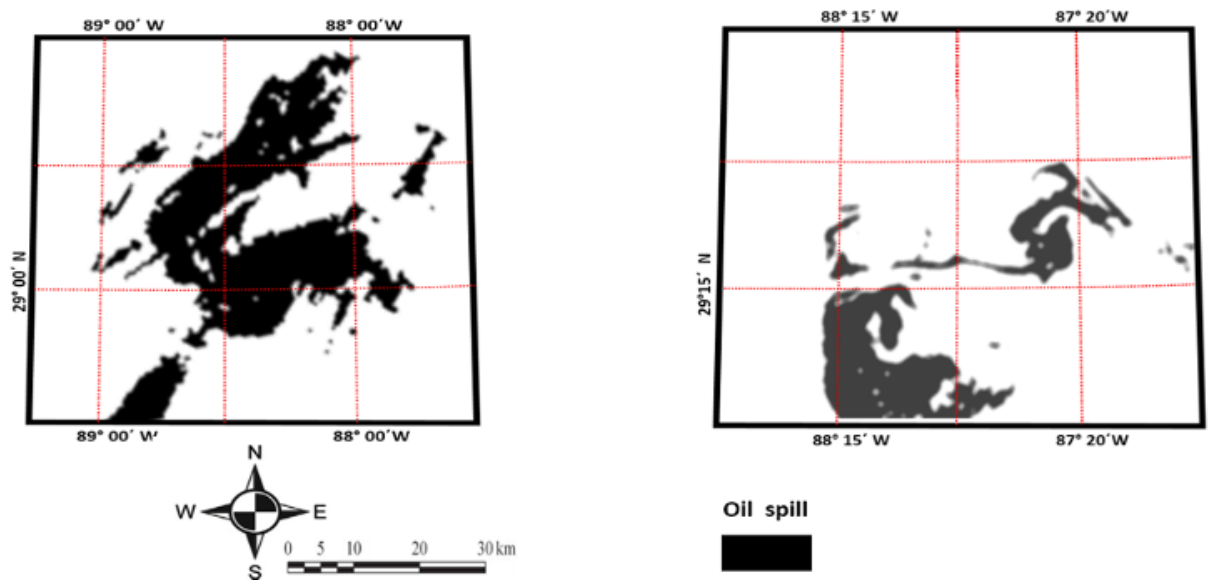

Oil spill

Fig. 10. Genetic algorithm oil spill automatic detection for RADARSAT-2 ScanSAR Narrow during: (a) 27 April, (b) 1 May, (c) 3 May, and (d) 5 May 2010.

approach that is considered to be a semi-automatic tool for oil spill detection. In contrast to the previous studies of Fiscella et al. (2000) and Marghany and Hashim (2011), the Mahalanobis classifier provides an oil spill classification pattern in which slight oil spill pixels can be distinguished from medium and heavy oil spill pixels. Nevertheless, the findings of this study are consistent with the results of Topouzelis et al. (2009a). The genetic algorithm was able to automatically extract oil spill pixels from the surrounding pixels without using a separate segmentation algorithm, as was done by Skrunes et al. (2012). Further, the GA algorithm is able to identify a small oil spill from large ones which has not been shown in previous studies (Fiscella et al. 2000, Marghany 2001, 2013, 2015; Topouzelis et al. 2009a, Marghany and Hashim 2011). 
(a)

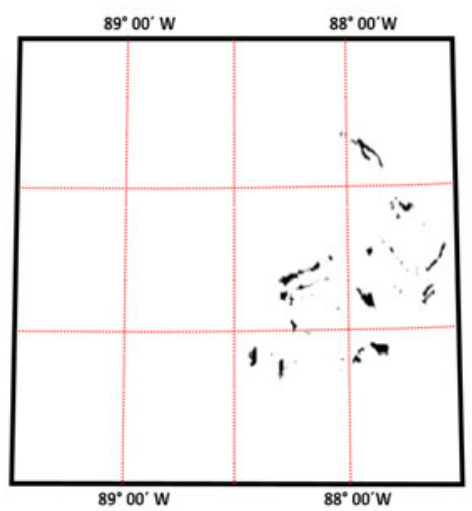

(c)

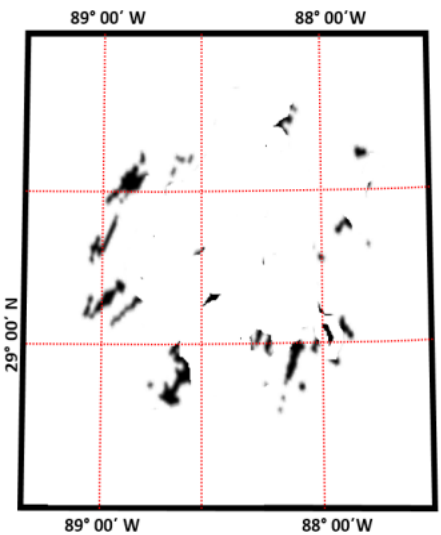

(b)

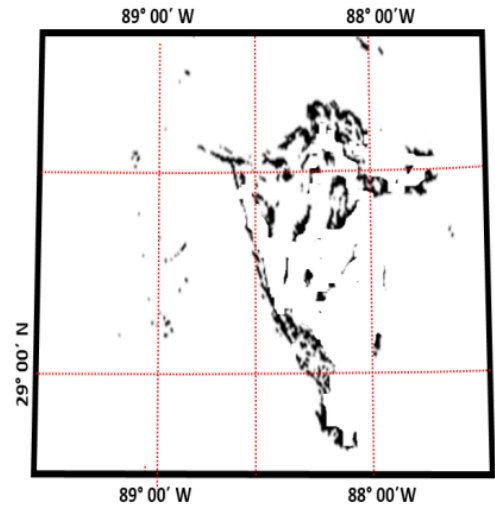

(d)

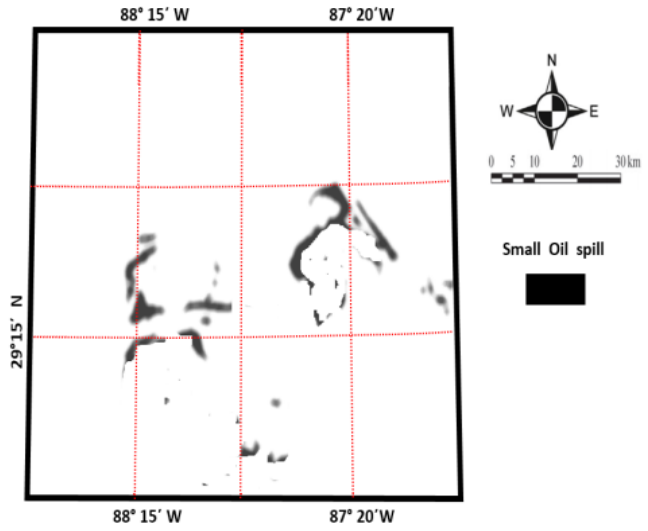

Fig. 11. Genetic algorithm for detection of small oil spills for RADARSAT-2 ScanSAR Narrow during: (a) 27 April, (b) 1 May, (c) 3 May, and (d) 5 May 2010.

The receiver-operating characteristic (ROC) curve presented in Fig. 12 indicates a significant difference in discrimination power among oil spill, look-alike and sea surface roughness pixels. In terms of the ROC area, small oil spill pixels exhibit an area difference of $30 \%$ compared with $60 \%$ for large oil spill pixels; $3 \%$ for look-alikes and $7 \%$ for sea roughness, and a $\rho$ value of less than 0.0005 ; these findings confirm the results of the study of Marghany (2013). Nevertheless, the work of Marghany (2013) cannot track small oil spill pixels from the large ones. It suggests that GA is an excellent promise for separating small oil spill pixels from the large ones and also from other features such as look-alikes and sea surface roughness. 


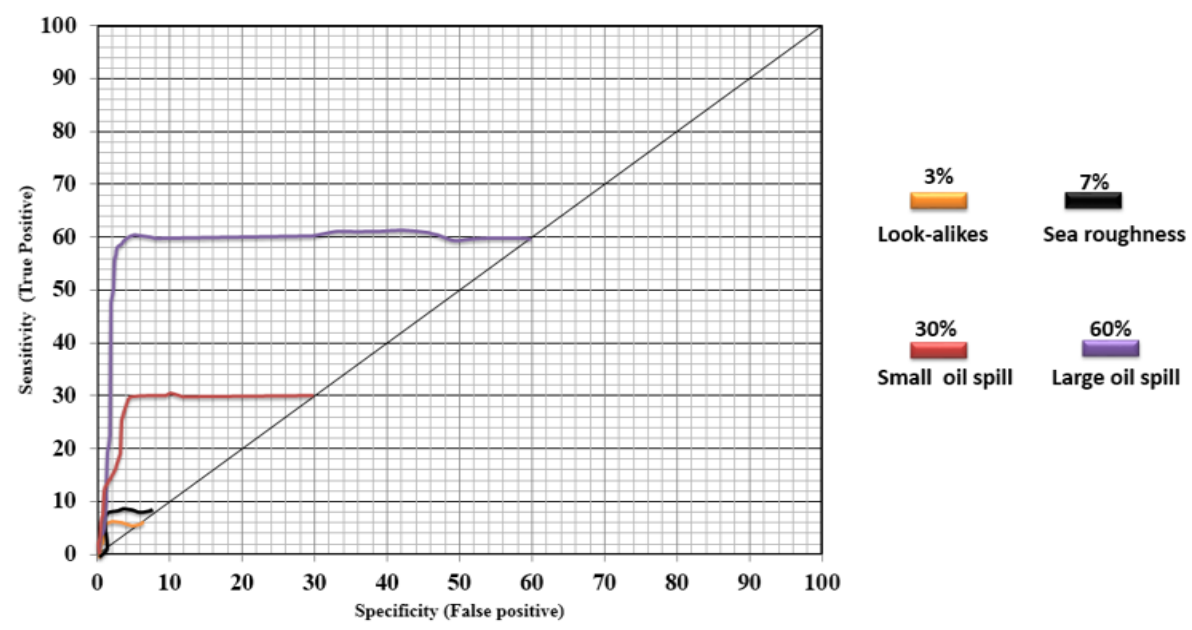

Fig. 12. ROC for discrimination of small and large oil spills using Genetic Algorithm (GA).

The power of the genetic algorithm lies in the crossover procedure. A new population is generated in each crossover process. As a result, multiple individual populations are examined by the fitness function and incorporated in subsequent populations began by small oil spill pixels. Thus, new populations of large oil spill are continuously generated based on the dissimilarities between two successive fitness values. In addition, the crossover procedure produces a more refined oil spill pattern, i.e., small and large oil spill pixels by despeckling and maintaining the morphology of the features of the oil spill pattern by virtue of the fitness function that is used to implement the oil spill pixel classification. Indeed, the fitness function selects a morphological pattern for the small oil spill pixels rather than large ones that are similar to the requested small and large spill arch types.

Previous studies were concerned with automatic detection of oil spilling from SAR images, which is based on the dark spot feature extraction and classification using Artificial Neural Networks (ANN) (Frate et al. 2000, Topouzelis et al. 2007, 2009a; Marghany and Hashim 2011), fractal (Marghany et al. 2009), texture algorithm (Marghany 2001), and Local Probability Maximization (LPM) (Lounis and Belhadj-Aissa 2014). Therefore, GA provided excellent automatic detection of small oil spill as compared to previous studies. In fact, automatic segmentation of oil spill problem is expressed as an optimization problem and Genetic Algorithm proficiently detects the global in a search space of SAR images and resolve the problem of parameter selection in SAR image segmentation. Further, genetic algorithm is implemented in SAR image segmentation to modify oil spill se- 
lected parameters in existing segmentation algorithms and pixel-level segmentation. Finally, genetic algorithm has the ability to determine the optimal number of regions of even small oil spill segmentation or to choose some features such as the size of the analysis window or some heuristic thresholds. This agrees with the finding of Mohanta and Sethi (2011).

In general, RADARSAT-2 SAR data deliver the extreme level of flexibility compared to other SAR sensors. Indeed, the couple of days for revisiting cycle of SCNB have provided both the wide area coverage and the high resolution imaging of oil slick detection and monitoring Macondo spill in the Gulf of Mexico. In this regard, for marine environmental monitoring, the ScanSAR modes with resolutions of $20-60 \mathrm{~m}$ and swath widths of $100-$ $300 \mathrm{~km}$ can provide an ideal trade-off between spatial resolution and areal coverage. This resolution is adequate for supporting oil spill automatic detection. Further, SCNB shows the potential even to identify small oil spill pixels from the surrounding large oil spill pixels by using such optimization tool as the Genetic Algorithm.

\section{CONCLUSIONS}

This study demonstrated the design of a tool for small and large oil spill detections in RADARSAT-2 SAR SCNB data using the genetic algorithms. SCNB data acquired in the Gulf of Mexico were investigated in this study. The study demonstrated that the crossover process and the fitness function used in the genetic algorithm was begun by generating small oil spill pixels and then allowed for the generation of an accurate oil slick pattern using the SCNB data which include small and large oil spill pixels. The excellent performance of the algorithm is evidenced by the $30 \%$ area difference achieved in the receiver operating characteristics (ROC) curve for small oil spill detection, compared to $60 \%$ for large oil spill, $3 \%$ for look-alikes, and $7 \%$ for sea roughness. The GA also exhibited excellent performance with respect to the SCNB data. In conclusion, the genetic algorithm can be used as a promising tool for the automatic detection of small and large oil spills in RADARSAT-2 SAR satellite data such as SCNB data.

\section{References}

Alpers, W. (2002), Remote sensing of oil spills. In: Proc. "Maritime Disaster Management" Symp., King Fahd University of Petroleum and Minerals, Dhahran, Saudi Arabia, 19-23.

Brekke, C., and A. Solberg (2005), Oil spill detection by satellite remote sensing, Remote Sens. Environ. 95, 1, 1-13, DOI: 10.1016/j.rse.2004.11.015. 
Caruso, M.J., M. Migliaccio, J.T. Hargrove, O. Garcia-Pineda, and H.C. Graber (2013), Oil spills and slicks imaged by synthetic aperture radar, Oceanography 26, 2, 112-123, DOI: 10.5670/oceanog.2013.34.

Cheng, A., M. Arkett, T. Zagon, R. De Abreu, D. Mueller, P. Vachon, and J. Wolfe (2011), Oil detection in RADARSAT-2 quad-polarization imagery: Implications for ScanSAR performance. In: Proc. SPIE 8179, SAR Image Analysis, Modeling, and Techniques XI, 19 September 2011, Prague, Czech Republic, 81790G, DOI: 10.1117/12.898358.

Choudhury, I., and M. Chakraborty (2006), SAR signature investigation of rice crop using RADARSAT data, Int. J. Remote Sens. 27, 3, 519-534, DOI: 10.1080/01431160500239172.

Cococcioni, M., L. Corucci, A. Masini, and F. Nardelli (2012), SVME: an ensemble of support vector machines for detecting oil spills from full resolution MODIS images, Ocean Dyn. 62, 3, 449-467, DOI: 10.1007/s10236-0110510-8.

Davis, L. (1991), The Handbook of Genetic Algorithms, Van Nostran Reingold, New York, $385 \mathrm{pp}$.

Fingas, M., and C. Brown (2014), Review of oil spill remote sensing, Mar. Pollut. Bull. 83, 1, 9-23, DOI: 10.1016/j.marpolbul.2014.03.059.

Fiscella, B., A. Giancaspro, F. Nirchio, P. Pavese, and P. Trivero (2000), Oil spill detection using marine SAR images, Int. J. Remote Sens. 21, 18, 35613566, DOI: 10.1080/014311600750037589.

Frate, F.D., A. Petrocchi, J. Lichtenegger, and G. Calabresi (2000), Neural networks for oil spill detection using ERS-SAR data, IEEE Trans. Geosci. Remote Sens. 38, 5, 2282-2287, DOI: 10.1109/36.868885.

Gade, M., W. Alpers, H. Hühnerfuss, H. Masuko, and T. Kobayashi (1998), Imaging of biogenic and anthropogenic ocean surface films by the multifrequency/ multipolarization SIR-C/X-SAR, J. Geophys. Res. 103, C9, 18851-18866, DOI: 10.1029/97JC01915.

Garcia-Pineda, O., I.R. MacDonald, X. Li., C.R. Jackson, and W.G. Pichel (2013), Oil spill mapping and measurement in the Gulf of Mexico with Textural Classifier Neural Network Algorithm (TCNNA), IEEE J. STARS 6, 6, 1-9, DOI: 10.1109/JSTARS.2013.2244061.

Grimaldi, C.S.L., I. Coviello, T. Lacava, N. Pergola, and V. Tramutoli (2011), A new RST-based approach for continuous oil spill detection in TIR range: The case of the deepwater horizon platform in the Gulf of Mexico. In: Y. Liu, A. MacFadyen, Z.-G. Ji, and R.H. Weisberg (eds.), Monitoring and Modeling the Deepwater Horizon Oil Spill: A Record-Breaking Enterprise, American Geophysical Union, Washington, 19-31.

Guo, Y., and H.Z. Zhang (2014), Oil spill detection using synthetic aperture radar images and feature selection in shape space, Int. J. Appl. Earth Observ. Geoinf. 30, 146-157, DOI: 10.1016/j.jag.2014.01.011. 
Ivanov, A., M.X. He, and M.Q. Fang (2002), Oil spill detection with the RADARSAT SAR in the waters of the Yellow and East China Sea: A case study. In: 23rd Asian Conference on Remote Sensing, 13-17 November 2002, Nepal, Asian Remote Sensing Society, Japan, 1, 1-8 (CD rom).

Kahlouche, S., K. Achour, and M. Benkhelif (2002), A new approach to image segmentation using genetic algorithm with mathematical morphology. In: Proc. 2002 WSEAS Int. Conf., 12-16 June 2002, Cadiz, Spain, 1-5, available from: http://www.wseas.us/elibrary/conferences/spain2002/papers/443164.pdf.

Lounis, B., and A. Belhadj-Aissa (2014), Sea SAR images analysis to detect oil slicks in Algerian coasts, J. Math. Modell. Algorithms Operations Res. 83, 1, 9-23, DOI: 10.1007/s10852-014-9250-3.

Marghany, M. (2001), RADARSAT automatic algorithms for detecting coastal oil spill pollution, Int. J. Appl. Earth Observ. Geoinf. 3, 2, 191-196, DOI: 10.1016/S0303-2434(01)85011-X.

Marghany, M. (2013), Genetic algorithm for oil spill automatic detection from ENVISAT satellite data. In: B. Murgante, S. Misra, M. Carlini, C.M. Torre, H.-Q. Nguyen, D. Taniar, B.O. Apduhan, and O. Gervasi (eds.), Computational Science and Its Applications - ICCSA 2013, Lecture Notes in Computer Science, Vol. 7972, Springer, Berlin Heidelberg, 587-598, DOI: 10.1007/978-3-642-39643-4_42.

Marghany, M. (2015), Multi-objective entropy evolutionary algorithm for marine oil spill detection using cosmo-skymed satellite data, Ocean Sci. Discuss. 12, 3, 1263-1289, DOI: 10.5194/osd-12-1263-2015.

Marghany, M., and M. Hashim (2011), Comparative algorithms for oil spill detection from multi mode RADARSAT-1 SAR satellite data. In: B. Mur-gante, O. Gervasi, A. Iglesias, D. Taniar, and B.O. Apduhan (eds.). Computational Science and Its Applications - ICCSA 2011, Lecture Notes in Computer Science, Vol. 6783, 318-329, DOI: 10.1007/978-3-642-21887325.

Marghany, M., A.P. Cracknell, and M. Hashim (2009), Modification of fractal algorithm for oil spill detection from RADARSAT-1 SAR data, Int. J. Appl. Earth Observ. Geoinf. 11, 2, 96-102, DOI: 10.1016/j.jag.2008.09.002.

MDA (2009), RADARSAT-2 product description, MacDonald, Dettwiler and Associates Ltd., available from: http://www.gs.mdacorporation.com (accessed: 7 March 2014).

Michalewicz, Z. (1994), Genetic Algorithms + Data Structures = Evolution Programs, 2nd ed., Springer Verlag, New York, 340 pp.

Mohanta, R.K., and B. Sethi (2011), A review of genetic algorithm application for image segmentation, Int. J. Comput. Technol. Appl. 3, 2, 720-723.

NOAA OR\&R (2013), Deepwater horizon trajectory map archive, National Oceanic and Atmospheric Administration, Washington, DC, USA, available from: http://archive.orr.noaa.gov (accessed: 23 October 2013). 
NOAA/NESDIS (2013), National environmental satellite information service, experimental marine pollution surveillance daily composite product, National Oceanic and Atmospheric Administration, Washington, DC, USA, available from: http://satepsanone.nesdis.noaa.gov/OMS/disasters/Deepwater Horizon/composites/2010/ (accessed: 8 August 2014).

RADARSAT-2 (2014), Satellite characteristics, Canadian Space Agency, available from: http://www.asc-csa.gc.ca/eng/satellites/radarsat/radarsat-tableau.asp (accessed: 7 March 2014).

Shay, L.K., B. James, J.K. Brewster, P. Meyers, E. Claire, E.C. McCaskill, E. Uhlhorn, F. Marks, G.R. Halliwell Jr., O. Martin, O.M. Smedstad, and P. Hogan (2011), Airborne ocean surveys of the loop current complex from NOAA WP-3D in support of the "Deepwater Horizon" oil spill. In: Y. Liu, A. MacFadyen, Z.-G. Ji, and R.H. Weisberg (eds.), Monitoring and Modeling the Deepwater Horizon Oil Spill: A Record-Breaking Enterprise, American Geophysical Union, Washington, D.C., 131-151, DOI: 10.1029/ 2011 GM001101.

Shirvany, R., M. Chabert, and J.-Y. Tourneret (2012), Ship and oil-spill detection using the degree of polarization in linear and hybrid/compact dual-pol SAR, IEEE J. STARS 5, 3, 885-892, DOI: 10.1109/JSTARS.2012.2182760.

Sivanandam, S.N, and S.N. Deepa (2008), Introduction to Genetic Algorithms, Springer, Berlin Heidelberg.

Skrunes, S., C. Brekke, and T. Eltoft (2012), An experimental study on oil spill characterization by multi-polarization SAR. In: Proc. 9th European Conf. on Synthetic Aperture Radar, 23-26 April 2012, Nuremberg, Germany, 139142.

Topouzelis, K., V. Karathanassi, P. Pavlakis, and D. Rokos (2007), Detection and discrimination between oil spills and look-alike phenomena through neural networks, ISPRS J. Photogram. Remote Sens. 62, 4, 264-270, DOI: 10.1016/j.isprsjprs.2007.05.003.

Topouzelis, K., D. Stathakis, and V. Karathanassi (2009a), Investigation of genetic algorithms contribution to feature selection for oil spill detection, Int. J. Remote Sens. 30, 3, 611-625, DOI: 10.1080/01431160802339456.

Topouzelis, K., V. Karathanassi, P. Pavlakis, and D. Rokos (2009b), Potentiality of feed-forward neural networks for classifying dark formations to oil spills and look-alikes, Geocarto Int. 24, 3, 179-191, DOI: 10.1080/ 10106040802488526.

Velotto, D., M. Migliaccio, F. Nunziata, and S. Lehner (2011), Dual-polarized terraSAR-X data for oil-spill observation, IEEE Trans. Geosci. Remote Sens. 49, 12, 4751-4762, DOI: 10.1109/TGRS.2011.2162960.

Walker, N.D., C.T. Pilley, V.V. Raghunathan, E.J. D’Sa, R.R. Leben, N.G. Hoffmann, P.J. Brickley, P.D. Coholan, N. Sharma, H.C. Graber, and R.E. Turner (2011), Impacts of loop current frontal cyclonic eddies and wind forcing on the 2010 Gulf of Mexico oil spill. In: Y. Liu, A. MacFadyen, 
Z.-G. Ji, and R.H. Weisberg (eds.), Monitoring and Modeling the Deepwater Horizon Oil Spill: A Record-Breaking Enterprise, American Geophysical Union, Washington, DC, 103-116, DOI: 10.1029/2011GM001120.

Xu, L., J. Li, and A. Brenning (2014), A comparative study of different classification techniques for marine oil spill identification using RADARSAT-1 imagery, Remote Sens. Environ. 141, 14-23, DOI: 10.1016/j.rse.2013.10. 012.

Zangari, G., (2010), Risk of global climate change by BP oil spill, available from: http://www.associazionegeofisica.it/OilSpill.pdf (accessed: 7 March 2014).

Zhang, B., W. Perrie, X. Li, and W. Pichel (2011), Mapping sea surface oil slicks using RADARSAT-2 quad-polarization SAR image, Geophys. Res. Lett. 38, 10, L10602, DOI: 10.1029/2011GL047013.

Zhang, Y., H. Lin, Q. Liu, J. Hu, X. Li, and K. Yeung (2012), Oil-spill monitoring in the coastal waters of Hong Kong and vicinity, Mar. Geod. 35, 1, 93-106, DOI: $10.1080 / 01490419.2011 .637872$.

Zhang, Y., Y. Li, and H. Lin (2014), Oil-spill pollution remote sensing by synthetic aperture radar. In: M. Marghany (ed.), Advanced Geoscience Remote Sensing, InTech, Rijeka, 27-50, DOI: 10.5772/57477, available from: http:// www.intechopen.com/books/advanced-geoscience-remote-sensing/oil-spillpollution-remote-sensing-by-synthetic-aperture-radar (accessed: 7 August 2014).

Zhao, J., M. Temimi, H. Ghedira, and C. Hu (2014), Exploring the potential of optical remote sensing for oil spill detection in shallow coastal waters-a case study in the Arabian Gulf, Opt. Express 22, 11, 13755-13772, DOI: 10.1364/OE.22.013755.

Received 12 September 2014

Received in revised form 17 August 2015

Accepted 29 October 2015 